\title{
Japan's NASDA under fire on launch failure
}

[TOKYO] The strategy of Japan's National Space Development Agency (NASDA) needs to be overhauled after the failure of three space missions in nine months, says Sadakazu Tanigaki, director-general of the Science and Technology Agency.

The space agency came under fire at a meeting held by Japan's Space Activities Commission over NASDA's slow investigation of the recent failure of an H-II rocket launch. The launcher, carrying the world's largest telecommunications satellites, failed to reach geostationary orbit after an engine failure (see Nature 391, 832; 1998).

The failure came as a severe shock to NASDA, whose two previous missions, the Advanced Earth Observation Satellite and the Advanced Land Observation Satellite, also ended in failure (see Nature 388, 105; 1997). An investigation has revealed an abnormality in the combustion chamber of H-II's second-stage LE5A engine, manufactured by Mitsubishi Heavy Industries. But the precise cause of the failure is still unknown.

Toshihiko Fujita of NASDA, who is responsible for the investigation, suggests the construction chamber may not have been strong enough. But he says it is unlikely there was a flaw in its design, pointing out that NASDA's past 30 medium-sized and large rockets have all been launched successfully.

Part of the problem appears to lie in the failure of NASDA to communicate adequately with the contractor who built the engines. Although the agency has a scheme

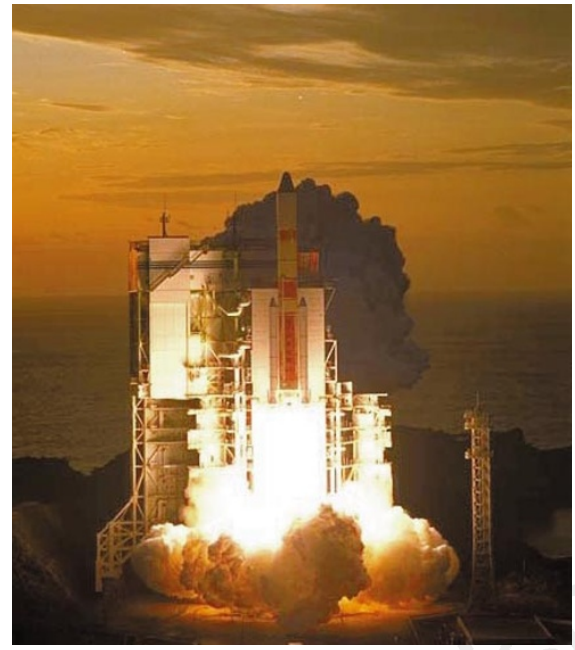

In happier times: a Japanese H-II rocket blasts off successfullyfrom Tanegashima Space Centre.

to send its engineers to contractor companies, only one engineer has gone so far.

Although the immediate concern is to find the cause of the engine failure, others fear that the prolonged investigation may deter Japan from entering the international commercial satellite business.

Rocket System, a commercial satellitelaunching company collaborating with more than 70 space-related companies, has signed a contract with Hughes Space and Communication International (HSCI) and Space Systems/Loral to launch more than 20 satellites using a new $\mathrm{H}-\mathrm{II}$ launch vehicle. The total cost of the operation, planned to happen between 2000 and 2007, is thought to be about $¥ 200$ billion (US $\$ 1.5$ billion).

The two US commercial satellite manufacturers have so far shown little concern about the failure of H-II. Robert Berry, president of Space Systems/Loral, says "failures are indispensable to space development”.

Although all $\mathrm{H}$-II rockets have previously been developed indigenously, the new H-IIA will, as part of NASDA cost-cutting, be built using imported materials and subsystems. This is expected to reduce the cost from $¥ 18$ billion per launch to less than ¥8.5 billion. "Now that Japan has an established technology for rocket development, the next step is to minimize the cost to enter global competition," says Hiroshi Imamura, director of Rocket System.

Imamura says inspection can be automated, and the construction of the rockets, which normally takes three years, can be reduced to two. The ultimate goal, he says, is to mass-produce rockets to launch them more frequently - only one $\mathrm{H}-\mathrm{II}$ is, at present, launched each year in Japan.

With just two-and-a-half years left until Japan joins the international commercial satellite business, Imamura suggests that mass production of rockets could help improve mechanical reliability. "Since we only build one or two rockets each year, it is difficult for us to predict reliability, and increased production could help us improve our technology," he says. AsakoSaegusa

\section{Set clear priorities to win surplus cash, Canada's scientists told}

[OTTAWA] The budget may have ended 14 years of deficit cutting and freed Canada to consider new science initiatives (see Nature $392,7 ; 1998)$. But if science is to profit, hard choices have to be made and clear priorities set, as there will be stiff competition for the C $\$ 70$ billion (US $\$ 49$ billion) surpluses expected over the next three years.

This theme emerged from a colloquium on federal government support for science organized by the University of Ottawa's Program of Research on International Management and Economy (PRIME).

Robert de Cotret, a former president of the government's Treasury Board and now a faculty member of the university, spoke of February's budget as a "watershed" that enabled the government to consider projects formerly unthinkable. De Cotret also said the present government had shown a strong commitment to science and technology.

But other speakers agreed with Howard Alper, the university's vice-rector of research, who said that "putting money on the table will accomplish nothing" for science. Specific proposals were needed.

Alper's own proposals included: - more collaboration between the three research councils that provide grants what he called "tri-council partnerships"; - focusing research priorities on areas important to economic development, such as biopharmaceuticals, materials, information technology, and food and agriculture; - making strategic investments in international science and technology; - allowing cash contributions by foreign companies to university-industry partnerships, partly to promote job creation; - developing a programme to repatriate established, mid-career Canadian scientists now working abroad.

Dan Lane, the university's vice-dean of administration, complained that a lack of direction in both the fisheries and oceans and environment departments had led to confusion about goals for science.

There was general praise for the budget's restoration of council funding to 1995 levels and the establishment of the Millennium
Scholarship Fund. But J. Stephan Dupré, president of the Canadian Institute for Advanced Research, called the councils' increases mere "damage control".

Dupré said a big question was whether provincial governments would provide enough operating support for universities, citing scientific manpower shortages which universities were unable to correct.

Further caution was added by Don McDiarmid, of the Canadian Association of Physicists, who warned delegates not to expect industry to invest in basic research because it is not in its own interest. And Gilles Paquet, professor of public policy and management at the university, said that he saw "no action" on science in the budget and no evidence that Ottawa was seriously "looking at anything except infrastructure".

Moreover, he said, Canadian scientists were not helpful. "We still have a scientific community that is to a great extent corrupted by [the view that government should simply] send the money and not ask any questions," Paquet said. David Spurgeon 